Article

\title{
Economic benefits and treatment progress as determinants of the sustainability of Vietnamese voluntary co-located patients clusters
}

\author{
Quan-Hoang Vuong \\ School of Business, FPT University, Hanoi, Vietnam
}

Significance for public health

Poor patients in transitioning economy, Vietnam included, to a market model oftentimes live in desparate economic hardship. Voluntary co-location emerged to be a solution for the poor in absence of adequate social supports for public health. This short report represents one of the first investigations into the social psychology and underlying economics of those communities. The understanding would likely be useful for planning and designing future policy response for this critical aspect of public health in Vietnam. By appropriate interventions and supports, the government and society can help to reduce economic inequality and deliver better inclusive economic growth.

\section{Abstract}

Background. Over the past 15 years or so, in Vietnam, a phenomenon has steadily grown more and more widespread: the forming of co-located patients communities. Poor patients choose to live together, seeking/lending supports from/to one another. Despite the undeniable existence of these communities, little is researched or known about how co-located patients perceive the value of what they receive as cluster members, or how they assess their future connection to the communities they are living in.

Materials and Methods. The study employs multiple logistic regressions method to investigate relationships between factors such as perceived satisfaction from community-provided financial means, reported health improvements, along with patients' shortand longer-term commitments to these communities.

Results. The results suggest meaningful empirical relationships: 1) between, on one hand, gender, perceived values and sustainability of patients communities, financial stress faced by patients and the financial benefits they received from the community, and, on the other hand, their propensity to stay connected to it; and 2) between economic conditions, length of stay with a community, general level of satisfaction, health improvements on one hand and long-term commitment to these communities on the other hand.

Conclusions. Patients who choose to stick to co-location clusters do so for an economic reason: finding means to fight their financial hardship. This may suggest a degree of complication higher than one would have thought in dealing with poor patients from a social point of view. Concretely, the majority of the public only focuses on charity programs and in-king donations, while ignoring the more sustainable - and, at the same time, more complicated - alternative which is to create suitable income-generating jobs for patient. In addition, patients are not only those who seek to ask for supports but can potentially be the donors contributing to the sustainability of those voluntary communities.

\section{Introduction}

The co-location of poor patients in small clusters within the urban areas, mostly near major healthcare centers, is an emerging reality of human affairs in larger cities in Vietnam, such as Hanoi. Despite their daily existence, reports on this socioeconomic phenomenon in the extant literature of social and public health are scarce. As a society in transition, currently carrying out and implementing changes in, among other things, its healthcare system, Vietnam is subject to uncertainties of healthcare outcomes, with the most vulnerable groups being the poor. ${ }^{1,2}$ Unfortunately, colocated patients fall into the most desperate category among all. They need co-located communities (also called clusters) for different reasons, but mainly as a type of economic intervention selforganized by patients to help each other ease hardships during treatment. This is especially important because serious or chronic illnesses are usually accompanied by high treatment costs, which would deeply affect the financial status of patients, even when they have been prepared. ${ }^{3-5}$ Community supports help reduce costs not only by providing direct donations and/or loans but also by creating suitable jobs, facilitating communication, and sharing experiences in life and treatments. 6,7

According to a survey in Japan, at least $80 \%$ the population need to consult or seek help from surrounding communities. ${ }^{8}$ In Sweden, the project of combining healthcare services, social services and social insurance for specific groups of patients was developed early with promising results. ${ }^{9}$ This shows that the model of co-located patients community is applicable and beneficial not only to developing countries such as Vietnam but also to developed countries as an effective social measure to reduce medical costs, increasing the success of the treatment process. ${ }^{10}$

Healthcare researchers have reported evidence suggesting the value of financing schemes such as universal health coverage (UHC) or micro health insurance (MHI) in mitigating health risk for the poor. ${ }^{11}$ Nonetheless, underdeveloped health financing systems in most developing countries are still unable to cope with the constant shifting in patients' poverty landscape in this fast-changing period. ${ }^{12}$

There is evidence indicating that Vietnamese patients have been facing higher risk of destitution, ${ }^{13}$ and decreasing quality of life. ${ }^{2,14,15}$ The problem appears to have been more complex than it has been thought to be, for various reasons: from undeveloped healthcare and health financing systems to complication of treatments for chronic diseases ${ }^{12,13,16}$ or complicated policy-making processes. $^{15}$

Therefore, it is, in a way, natural for an increasing number of Vietnamese patients to seek social and financial backing by living together in voluntary co-location clusters ${ }^{17}$ where they expect to lend and receive supports to and from one another; which could possibly help to reduce burdens, to share resources, as well as to 
provide for their information needs. , $^{9,18}$

The ultimate rationale for the existence of those communities is to improve patients' quality of life, ${ }^{16,18,19}$ thus enhancing their well-being as well as their perception of the healthcare benefits of their long-term treatment. ${ }^{20}$ This expectation is realistic even for patients in countries with better healthcare and well-functioning health financing systems such as Sweden, ${ }^{21}$ where co-financing and different forms of collaborations remain among efficient choices of providing healthcare resources to the public. It is not difficult for us to see that for a country with an average income of US \$ 2300 (as of 2016) such as Vietnam, patients with lower socioeconomic status face more hurdles during their treatments as costs emerge to be a major barrier to basic treatment facilities, quality medicine and adequate care giving. ${ }^{13,16,22,23}$ Therefore, co-location clusters that help share basic amenities and reduce costs of accommodation for some become the only choice. ${ }^{24-26}$ These people, upon joining the community, would expect the communities to help satisfy part of their needs with either in-kind benefits that the communities may be able to offer or financial means, ${ }^{2}$ including income-generating activities. ${ }^{27,28}$ At the same time, living in such a group gives them a higher chance of drawing attentions from the public and social workgroups dealing with public health matters. This being said, real-world implementation always faces difficultto-solve challenges, and the implementation of such communitites makes no exception. ${ }^{29,30}$

The questions for us, who know little about these communities, are: How do member patients of voluntary co-location clusters perceive the value of financial benefits from the community? And, once their medical treatments are over, will they continue to stay connected and/or committed to the community? This knowledge is as it may help us learn more about the prospects and sustainability of the communities.

This short article attempt to answer these questions, employing survey data collected from the patients. Before moving on to a description of the datasets and methods, two major hypotheses will be presented, to make our research questions more specific and feasible to answer with the data in hand.

The statement of problem following our previous discussion is reflected through the main research questions (RQ), which are going to be analyzed to eventually conclude with insights reported in this article. The questions are as follows.

\section{Research questions}

$R Q 1$. Patients' short-term (i.e., only during their treatments) commitment and bonding to the community is influenced by gender, perceived future community growth prospects, their degree of financial shortage and satisfactory financial benefits provided by the community.

RQ2. Patients' medium- to long-term (i.e., post-treatment bonding) commitment to the co-location community is affected by economic conditions, length of stay in co-location communities, their perceived overall satisfaction and actual health improvement.

\section{Materials and Methods}

\section{Sampling}

This research is performed based on the analysis of a sample of 336 patients who have voluntarily co-located in four clusters in Hanoi, Vietnam, called patients villages (Xom Than, Ngoc Hoi, Nha Luu Tru, Tro Nhi), during December 2015-March 2016. The oldest patient is 84 ; the youngest are barely months-old children.
These clusters were gradually formed over time, and their populations have also changed. The birth of these co-location communities was influenced by Vietnam's transitional sociodemographic factors, and these four were selected based on the public's awareness and media coverage about them. They are to a certaint extent relatively established with sign of growth in recent years. A large portion of patients in the clusters Xom Than, Ngoc Hoi, Nha Luu Tru have a CKD, and need periodic, costly treatments. A particularity worth remarking: the cluster Tro Nhi primarily accommodates families with children having serious illnesses such as congenital heart diseases or spastic cerebral palsy.

Members of these clusters mostly come from rural and lagging regions, mountainous areas, in the North (about $80 \%$ ). They are poor and desperate workers who knew about patients' villages through words of mouth introduction by their friends and acquaintances (98\%). The patients have little choice but to stay in Hanoi, where most important hospitals with adequate facilities and capable health professionals are located, in order to have long-term treatments. To reduce costs of living in an increasingly expensive Hanoi, many patients chose to rent low-cost houses and share them among a growing number of patients. These low-cost houses are shabby, poorly constructed, dark and small. Beyond the treatment time in hospitals, patients usually do many odd jobs, such as selling cheap tea, working as a street vendor, being an independent motorbike driver, delivering goods, etc. , to earn their living and pay part of the medical costs. Sometimes, the patients live in these communities receive financial and/or in-kind supports from the public and charity organizations.

As of the time survey, Xom Than and Nha Luu Tru have the greater number of members, corresponding to $41 \%$ (128 people) and $38 \%$ (139 people) of the sample, respectively. The others (Tronhi, Ngochoi) have 43 and 26 members, respectively. Every member has been participating in their cluster for a considerable period of time. Most of the people in Xom Than and Ngoc Hoi have joined the cluster more than 1 year (Figure 1).

This sample is not randomly taken, but deliberately chosen to observe behavior. The authors initially expected a greater number of patients, but, as it turned out, the practice of living together from inter-dependence only occurs in certain groups. The sample consists of 336 observations, which can be considered relatively small compared to the majority of social studies in Vietnam and nearby regions. However, in this specific case where uniquely co-located patients are concerned, we have confidence that our dataset is, quantity-wise, the most complete in the area of Hanoi. Moreover,

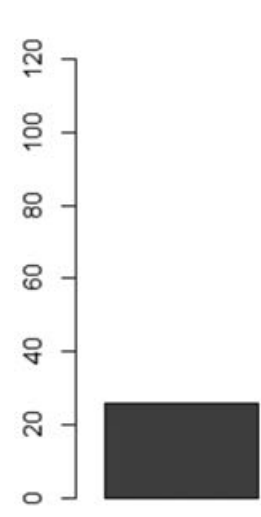

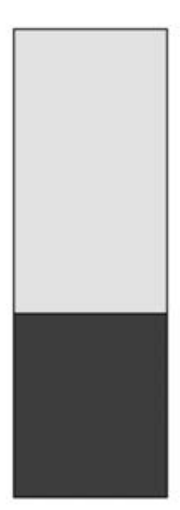

ngochoi

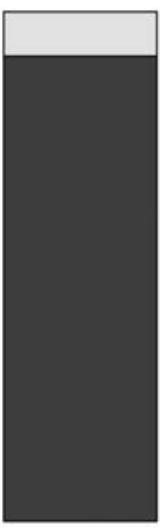

than

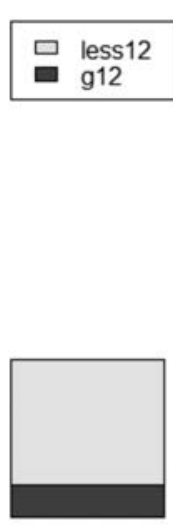

tronhi
Figure 1. Distribution of short- and long-stay patients among clusters. 
the issue of sample size and quality control has been a problem in Vietnam. By choosing accurate data control over large sample sizes, we hope to reinforce the fidelity of this study.

Based on the respondents' behavior as well as their ability to answer accurately, the analysis mainly used binary variables. Patients, being in poverty and having little contact with society, tend to be marginalized by society, even in case of improved socioeconomic status. One of the consequences of this is that patients are often afraid of communicating, especially to those whom they consider to be strangers. Therefore, our survey limited the choice of answers to: i) save time for the patients and avoid excessive talking; and ii) enable cluster leaders and out-sourced collaborators capable of giving detailed instructions to participants and filling up the questionnaire. With this, we aim to obtain clear and accurate answers. In fact, this method proved to bring positive results and a more effective coordination, compared to some of our previous investigation.

In addition, giving many complex answer choices often makes it difficult for both the data-gathering team and respondents. On one hand, collaborators often do not know the patients' background, whether it concerns their illness or their other experiences. On the other hand, not all patients can understand complex questions or answer choices. The study's goal is not to give a thorough sociopsychological review; rather, it aims to help society recognize the value of health data as well as social cooperation in community health surveys. This target has partially been achieved, because after we carried out our survey, some patients opened up to us and expressed interest in further cooperation regarding future projects. We consider this a step forward; it may even lead to closer studies in the life of patients' communities. The issues could even be revisited in the future and compared to current results, which is still quite modest.

\section{Data collection}

The raw data employed in this research have been collected by the research team at Hanoi-based Vuong \& Associates through direct interviews. The survey team is divided into small group and conduct face-to-face interview patients in each cluster to fill up questionnaires. Before each interview, we took care to clearly present to the patient the purpose of survey, explain the questionnaire and guarantee our commitment to keep patients' privacy. Patients voluntarily participated in this survey and their responses were originally noted on questionnaires, then encoded and saved on computer using MS Excel.

\section{Data Set}

Following our research questions as proposed in the preceding discussion, they are structured into four contingency tables, representing four datasets.

\section{Data for RQ1}

RQ1 evaluate several factors affecting patients' decision to be more integrated into clusters during treatment. Earlier, we refer to the differences in the selection of patients by gender and by their perceived values and growth of the community in the future. Patients' commitment (Commitment) to their community serves as response variables in this investigation: indisp.dur (the cluster feels indispensable to them and they will continue to be committed) and disp.dur (they will not be as committed to the cluster after treatment). Independent variables include Sex (options: male, female) and the patients' evaluation of the scale of clusters in the future (Scalefut), consisting of two categories: expansion (will be expanded) and contraction (will either stabilize or narrow down).
Table 1 shows the distribution of people following three factors.

In general, the men:women ratio in the community is relatively balanced. Table 1 also shows that nearly half of the people have positive view about the development of clusters in the future.

Later, the dataset is used to assess the effect of patients' various degrees of financial needs on their expectation from the community; their degree of satisfaction is given in Table 2. The examination shows that the gap between expectations and actual deliveries has an important influence on patients' long-term commitment to their co-location community. The second hypothesis of RQ1 investigates patients' perception of their own participation in these clusters as indispensable or not, during their medical treatment period, as influenced by two groups of predictors: their financial needs (Need.fin) and actual income/money provision (Ben.fin) from the community, directly or indirectly.

In light of the above, Need.fin has two values: nonurg.fin and urg.fin, representing lower (non-urgent) and higher (urgent) degree of desperateness for financial help by a patient. Likewise, Ben.fin has two values met.fin and unmet.fin showing whether a patient assesses the financial benefits from the community to be satisfactory or not, respectively.

It can be learned from Table 2 that nearly $23 \%$ of respondents are under dire financial conditions which force them to desperately seek financial supports from the co-location community. From another angle - independent of the previous observation - about $26 \%$ of the total 336 have received adequate financial benefits while participating in the community, in forms of financial giving, income-generating activities or borrowings.

\section{Data for RQ2}

RQ2 looks into another aspect of the community: their future prospect of development, as influenced by patients' satisfaction. Following the same logic as presented with data for RQ1, we employ two regression models for two different groups of independent variable on the same response variable. The response and predictor variables are as follows

Response variables: They are categorical variables in the factor PostTr, used to observe patients' post-treatment commitment to these co-location clusters. The two variables include indisp.post (the community remains indispensable to them) and disp.post (they no longer feel the need to be committed to the community).

Table 1. Distribution of patients by gender, perceive growth of the community's scale in the future and commitment to the colocation community during their treatments.

\begin{tabular}{llcc} 
Sex & Scalefut & indisp.dur & disp.dur \\
\multirow{2}{*}{ Female } & Contraction & 32 & 58 \\
& Expansion & 12 & 65 \\
\multirow{2}{*}{ Male } & Contraction & 33 & 44 \\
& Expansion & 25 & 67 \\
\hline
\end{tabular}

Table 2. Distribution of patients following their perceived shortterm commitment against financial expectations and satisfaction while being co-located.

\begin{tabular}{llcc}
\multirow{2}{*}{ Need.fin } & Ben.fin & indisp.dur & disp.dur \\
\multirow{2}{*}{ nonurg.fin } & met.fin & 68 & 1 \\
& unmet.fin & 120 & 71 \\
\multirow{2}{*}{ urg.fin } & met.fin & 14 & 4 \\
& unmet.fin & 32 & 26 \\
\hline
\end{tabular}


Predictor variables: There are four groups of predictors $P E C$, Time, Expectation and ImprovedHealth. PEC is economic conditions, including two states: unstable income (unstable) and average or above income (stable). Time indicates the length of time that patients have lived in co-location communities until the survey happened, with two options: under 12 months (less12) and above 12 months (g12). Expectation indicates the patient's general satisfaction while living in the cluster, with values met.exp (satisfactory) and unmet.exp (not satisfactory). ImprovedHealth represents a patient's evaluation on the improvement of his/her own health conditions after living with the community, to which they can answer yes and placebo. Two datasets which are used for the two regression models in RQ2 are shown in Tables 3 and 4.

Observing Table 3 brings an interesting insight. The majority of patients $(75 \%)$ express a willing post-treatment commitment to their cluster. The percentage is even higher for patients still under treatment. It is understandable when $76 \%$ cluster members are living in unstable financial conditions.

Table 4 showed that about $93 \%$ respond that in general their expectations are met by the co-location mode of living. Nonetheless, only one fourth of the respondents report significant health improvement.

\section{Statistical analysis}

This study employs the baseline category logits (BCL) framework for analysis of categorical data. ${ }^{31}$ Since all the independent and dependent variables used in the regression model are binary variables, the BCL framework used to examine the empirical data sets estimates a generalized linear model (GLM) in the following form:

$\mathrm{g}\left(\mu_{i}\right)=\mathrm{X}_{i} \beta_{i}$

where, $\mu_{i}=\mathrm{E}\left(\mathrm{Y}_{i}\right)$, corresponding to $\mathrm{y}_{i}=\left(\mathrm{y}_{i 1}, \mathrm{y}_{i 2}\right)^{\mathrm{T}}$; row 2 of the model matrix $\mathrm{X}_{i}$ for observation $\mathrm{i}$ contains values of independent (also, predictor) variables for $\mathrm{y}_{i h}$, với $\mathrm{h}=\{1,2\}$. Estimated probabilities can be used to predict the possibilities of $Y$ in different conditions of $\mathrm{X}_{i}$.

Due to this set-up of the problem, and as $\pi_{j}(\mathrm{x})=\mathrm{P}(Y=j \mid \mathrm{x})$ represent a fixed setting for independent variables, with $\sum_{j} \pi_{j}(\mathrm{x})=1$, categorical data are distributed 2 categories of $Y$ as either binomial with corresponding probabilities $\{\pi(\mathrm{x}), 1-\pi(\mathrm{x})\}$. Thus, the BCL model aligns each dependent (response) variable with a baseline category: $\ln \left(\pi_{j}(\mathrm{x}) /\left(1-\pi_{j}(\mathrm{x})\right){ }^{32}\right.$

The set of empirical probabilities from binomial logits $\left\{\pi_{\mathrm{j}}(\mathrm{x})\right\}$ can be computed using the formula:

$\pi_{\mathrm{j}}(\mathrm{x})=\exp \left(\alpha_{j}+\beta_{j}^{\mathrm{T}} \mathrm{x}\right) /\left(1+\exp \left(\alpha_{j}+\beta_{j}^{\mathrm{T}} \mathrm{x}\right)\right)$

The coded names and values for those dichotomous variables are described in the corresponding data sets in the preceding sections of data sets (Tables 1-4).

Those interested in a possible alternative for modeling the data, the method of log-linear analysis, may refer to the real-world example provided in Vuong. ${ }^{33}$

The Wald test was used for testing the suitability of the model with two hypotheses: $\mathrm{H}_{0}: \beta_{j}^{\mathrm{T}}=\beta_{0}$ và $\mathrm{H}_{1}: \beta_{j}^{\mathrm{T}} \neq \beta_{0}{ }^{34}$ The general formula for Wald test is: $\mathrm{W}^{2}=\left(\beta_{j}^{\mathrm{T}}-\beta_{0}\right)^{2} / \mathrm{H}_{j} \sim \mathrm{X}_{1}^{2}$, in which $H_{\mathrm{j}}$ is the estimated variance of $\beta_{j}^{\mathrm{T}}$. Chi-square $\left(\chi^{2}\right)$ of the normal distribution is $X_{1}^{2}$ with one degree of freedom, and the sum of these two squares will distribute with two degrees of freedom. When testing the coefficients in the model are not simultaneously simultaneously zero, $\left(\beta_{0}=0\right)$, the Wald statistic simplifies to: $\mathrm{W}^{2}=$ $\left(\beta_{j}^{\mathrm{T}}\right)^{2} / \mathrm{H}_{j} \sim N(0,1)$.
The rejection of $\mathrm{H}_{0}$ shows that removing a factor will significantly affect the suitability of the model.

\section{Results}

Estimations for examining the above RQ1 and RQ2 are reported below. Reported coefficients and related statistics are evaluated using the statistical package R (v.3.2.3; see Appendix A).

\section{Estimation and results for RQ1}

Patients' short-term commitment and bonding to the community is influenced by gender, as well as satisfaction regarding clusterrelated benefits and perceived cluster future growth prospects

Table 5 provides results of our investigation into possible relationship between gender, future community growth prospects as perceived by patients, and patients' short-term commitment mostly limited to their treatment periods - to the co-location clusters under consideration.

All estimated coefficients are statistically significant $(\mathrm{P}<0.1)$, suggesting a significant relationship between predictor and response variables. But the effects caused by financial needs and received benefits appear to be opposite as: $\beta_{1}<0 ; \beta_{2}>0$.

Wald test was conducted to test the hypothesis of regression coefficients simultaneously being equal to zero. The result of chisquared test statistic of 20.9 with two degrees of freedom and P-

Table 3. Distribution of patients following their perceived longterm commitment against their satisfaction and health improvement.

\begin{tabular}{llcc} 
PEC & Time & indisp.post & disp.post \\
Stable & g12 & 11 & 33 \\
& less12 & 24 & 13 \\
Unstable & g12 & 8 & 160 \\
& less12 & 41 & 46 \\
\hline
\end{tabular}

Table 4. Distribution of patients following their perceived longterm commitment against their satisfaction and health improvement.

\begin{tabular}{llcc}
\hline \multirow{2}{*}{ Expectation } & ImprovedHealth & indisp.post & disp.post \\
& Yes & 64 & 12 \\
\multirow{2}{*}{ unmet.exp } & Placebo & 173 & 63 \\
& Yes & 7 & 2 \\
& Placebo & 8 & 7 \\
\hline
\end{tabular}

Table 5. Estimated results for model with dependent variable Commitment and independent variables Sex, Scalefut.

\begin{tabular}{lccc} 
& Intercept & Sex, male & Scalefut, expansion \\
& $\beta_{0}$ & $\beta_{1}$ & $\beta_{2}$ \\
logit & $0.672^{* * *}$ & $-0.467^{c}$ & $0.870^{* * *}$ \\
(indisp.durldisp.dur) & {$[3.371]$} & {$[-1.905]$} & {$[3.511]$} \\
\hline
\end{tabular}

Signif. codes: ${ }^{* * *} 0 ;{ }^{* *} 0.001,{ }^{*} 0.01,{ }^{c} 0.05$. Z-value in [square brackets]; baseline category for Sex: female; and, Scalefut: contraction. Residual deviance: 0.622 on 1 degree of freedom. 
value $=7 \times 10-04$ shows that the difference in coefficients of this model is statistically significant. The same test performed on other regressions can be found in in Appendix B.

The following equation is constructed using coefficients from Table 5:

$\ln \left(\pi_{\text {indisp.dur }} / \pi_{\text {disp.dur }}\right)=0.672-0.467 \times$ Male $+0.870 \times$ Expansion

From Eq. (1), we can calculate, for example, the probabily that a male person having positive views on community future growth is committed to their cluster during treatment as follows:

$\pi_{\text {indisp.dur }}=\mathrm{e}^{(0.672-0.467+0.870)} /\left(1+\mathrm{e}^{(0.672-0.467+0.870)}\right)=0.750$

This means that such a person is $75 \%$ likely to show commitment to their co-located cluster, while their treatment still lasts. Other conditional probabilities are calculated in a similar manner.

Patients' short-term commitment and bonding to the community is influenced by their degree of financial shortage and satisfactory financial benefits provided by the community

Logistic regression model with response variable Commitment and prediction variables Need.fin and Ben.fin, gave the following results: the intercept is $\beta_{0}=0.581(\mathrm{P}<0.001, \mathrm{z}=3.891)$; the coefficient of Need.fin at urg. fin is $\beta_{1}=-0.546(\mathrm{P}<0.1, \mathrm{z}=-1.880)$; and the coefficient of Ben.fin at met.fin is $\beta_{2}=2.353(\mathrm{P}<0.01, \mathrm{z}=2.352)$.

With $\mathrm{P}<0.1$, all regression coefficients are statistically significant, so we can confirm the empirical relationship between financial needs, received benefits and patients' short-term commitment - mostly limited to their treatment periods - to the co-location clusters under consideration.

Based on the regression coefficients, we construct the following equation Eq. (2):

$\ln \left(\pi_{\text {indisp.dur }} / \pi_{\text {disp.dur }}\right)=0.581-0.546 \times$ UrgFin $+2.353 \times$ MetFin

The largest coefficient is: $\beta_{2}=+2.353$. The intercept and of the effect of desperate financial needs have almost identical absolute values, but show different signs: $(+)$ and (-) respectively.

Eq. (2) prompts us to ask: If a patient's financial needs are satisfied thanks to their co-located community, how likely is the person to remain committed to the cluster until his/her medical treatments are completed?

The computing of $\pi_{\text {indisp.dur, }}$ under the conditions of both urg.fin and met.fin, yields an answer for the question:

$\pi_{\text {indisp.dur }}=\mathrm{e}^{(0.581-0.546+2.353)} /\left(1+\mathrm{e}^{(0.581-0.546+2.353)}\right)=0.916$

Patients are $91.6 \%$ certain of being committed to their colocated community, if said community succeeds in providing for their urgent needs.

\section{Estimation and results for $\mathrm{RQ2}$}

Patients' medium- to long-term commitment and bonding to the community is affected by economic conditions and length of stay in colocation communities

To evaluate the first relationship of RQ2, our logistic regression model with the dependent variable PostTr and two independent variables $P E C$, Time, collected all coefficients that are statistically significant with $\mathrm{P}$-value $<0.001$ : the intercept is $\beta_{0}=1.472$ $(\mathrm{P}<0.001, \mathrm{z}=4.709)$, the coefficient of $P E C$ at unstable is $\beta_{1}=1.208$ $(\mathrm{P}<0.001, \mathrm{z}=3.727)$ and the coefficient of Time at less 12 is $\beta_{2}=-$
$2.435(\mathrm{P}<0.001, \mathrm{z}=-7.843)$.

The empirical relationship between variables was thus confirmed. We can construct the regression equation Eq. (3) showing this relationship as follows:

$\ln \left(\pi_{\text {indisp.post }} t \pi_{\text {disp.post }}\right)=1.472+1.208 \times$ Unstable $-2.435 \times$ Less 12

The coefficient with the largest absolute value in Eq. (3) is $\beta_{2}=-$ 2.435. This shows that the amount of time the patient has spent living in the community will affect their choice of whether or not to remain committed. Two coefficients had opposite signs in the result, $\beta_{1}>0, \beta_{2}<0$, the absolute value of $\beta_{2}$ nearly doubling $\beta_{1}$. According to this, if a patient has lived in the co-location community for more than one year and is in unstable economic conditions, the likelihood that they will bond to community in long-term is nearly $94 \%$.

$\pi_{\text {indisp.post }}=\mathrm{e}^{(1.472+1.208)} /\left(1+\mathrm{e}^{(1.472+1.208)}\right)=0.936$

Patients' medium- to long-term commitment and bonding to the community is affected by their perceived overall satisfaction and actual health improvement

Using data in Table 3, we employ logistic regression to examine the effect of patients' expectations being met and positive health outcomes after treatment on their long-term (mainly posttreatment) commitment and contribution to the community. The reference category is unmet.exp for Expectation and yes for ImprovedHealth. The obtained results is the intercept $\beta_{0}=1.000$ $(\mathrm{P}<0.001, \mathrm{z}=6.891)$, the coefficient of Expectation $\beta_{1}=-0.743$ $(\mathrm{P}<0.1, \mathrm{z}=-1.649)$ and the coefficient of ImprovedHealth $\beta_{2}=0.720$ $(\mathrm{P}<0.05, \mathrm{z}=2.194)$.

As we use the conventional level of significance $10 \%$, all coefficients are statistically significant. $\beta_{1}<0, \beta_{2}>0$, and these two have similar absolute values $(\sim 0.7)$. Generally speaking, the results confirm a common-sense understanding about the patients' motivation prior to participating in co-location clusters: when reality doesn't meet their expectations, they are less willing of long-term commitment to the community; meanwhile, improved health conditions encourages them to continue contributing to their cluster, perhaps even after treatment.

The empirical relationship is provided in Eq. (4).

$$
\begin{array}{r}
\ln \left(\pi_{\text {indisp.post }} / \pi_{\text {disp.post }}\right)=1.000-0.743 \times \text { UnmetExp }+0.720 \times \text { Yes } \\
\operatorname{Eq}(4)
\end{array}
$$

Eq. (4) enables the computing of such probability under the conditions of unmet.exp and yes as follows:

$\pi_{\text {disp.post }}=1-\mathrm{e}^{(1.000-0.743+0.720)} /\left(1+\mathrm{e}^{(1.000-0.743+0.720)}\right)=0.273$

The result suggests that there is a $27.3 \%$ probability that a patient who experiences significant health improvement without satisfactory benefits from the community will not be committed to the community after his/her medical treatment has ended.

\section{Discussion}

By building a graph from the calculation of probability based on Eqs. (1-4), the impact of previously mentioned factors to patients' tendency regarding their bonds with the community in short-term and long-term will be shown clearly. 
Figure 2 shows the probability of patients being committed to the co-location community during treatment process (short-term), by gender and their evaluation of future community growth. Both lines in long-term commitment (indisp.dur) go downwards when moving from expansion to contraction; the contrary can be observed regarding lines in disp.dur. Thus, those who believe that the cluster will contract in the future are less likely to be willing to be committed to their community, even on short-term.

The figure also shows that women tend to be more attached to the community: the line Female lies above Male in Indisp.dur.

In evaluating financial-related issues, Figure 3 showed that those who have received significant financial benefits, in kind or in cash, from the community show a much stronger propensity to stay committed than those who do not. The difference is staggering, from 30 to 40 percentage points. Remarkably, there is a $91.6 \%$ probability that a patient whose financial needs were met by the community will be committed to it. It is also worth noting that the high absolute value of $\beta_{2}$ in Eq. (2) shows that patients' satifaction towards financial benefits from the community has a more signficant impact on their commitment to the cluster, more so than the urgency of their financial shortage. To evaluate the patients' long-term commitment, Figures 4 and 5 will provide more specific statements. Figure 4 indicates that unstable financial situations keep patients from separating with the clusters after their treatment process: they are more likely to commit to their
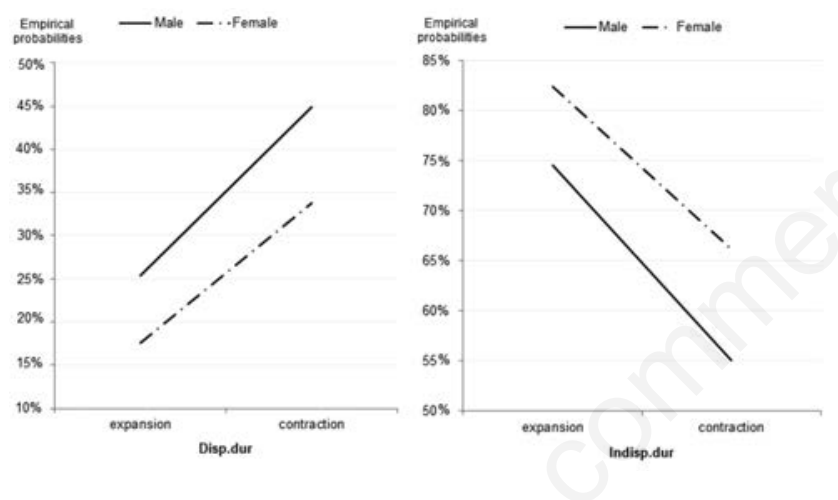

Figure 2. Probability of patients' short-term commitment to cluster by gender and personal evaluation of future community growth. co-location community than those with a stable income. This difference can go up to $29 \%$. Additionally, Figure 4 also shows that patients who have lived a long time in the community tend to bond deeper with it. Regarding probabilites of commitment to the community, there is an enormous difference between people who have only been living in the clusters since less than 1 year and those who have stayed for over 1 year, fluctuating between $38 \%$ and $54 \%$.

Beside economic issues, health is definitely a matter of concern. In Figure 5, the trends are similar for both those who observe real health improvements and those who only see a placebo effect, whether among committed (left) or non-committed (right) cluster members. However, between these latters, the trends are reversed, and the positions of the two lines (dash for significant improvement effect and solid for placebo effect) swap places. When moving from unmet.exp to met.exp, probability lines on indisp.aft, Figure 3 (left), tend to go up; while those on disp.aft, Figure 3(right), tend to go down. It confirms that patients' satisfaction will increase their attachment to the clusters after their treatment. On the figure indisp.aft, the line yes being above placebo shows that patients tend to bond more with the cluster when their health status is improved, and vice-versa. In addition, Appendix $\mathrm{C}$ also provides a data set that replaces the financial expectation by in-kind benefits, for which the in-kind benefits show similar effects to the expectation in RQ1.
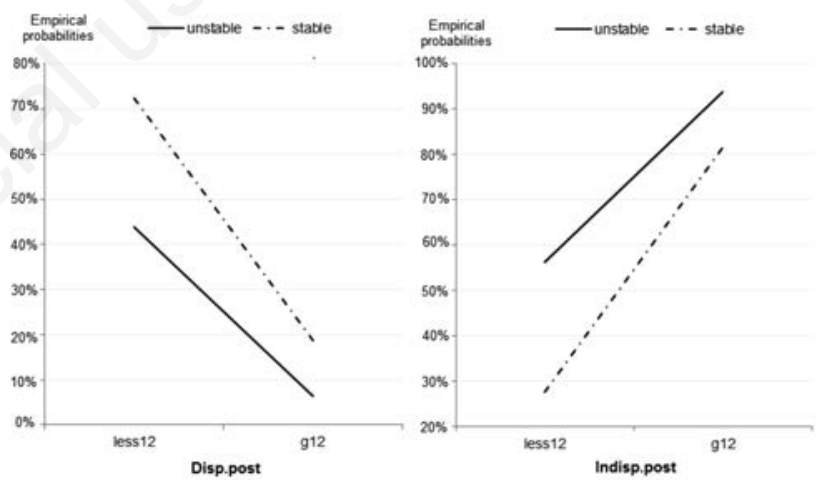

Figure 4. Probabilities of patients' long-term commitment to cluster by patients' economic conditions and length of stay

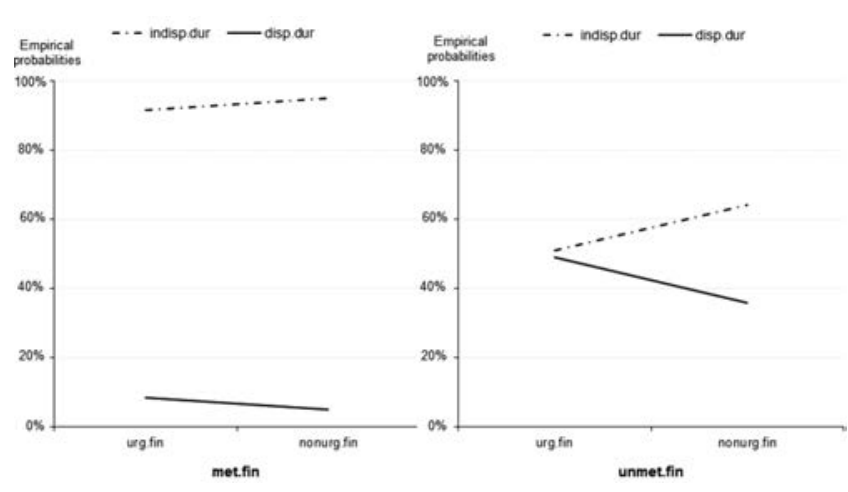

Figure 3. Probabilities of patients' short-term commitment by urgency of financial needs and satisfaction towards benefits received from the community.
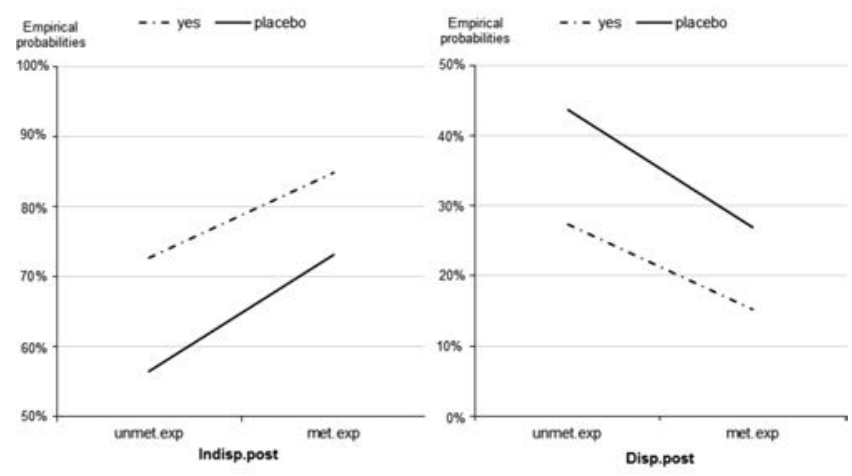

Figure 5. Probabilities of post-treatment commitment to cluster by degree of satisfaction and health improvement 


\section{Conclusions}

The above observations lead to important insights on the future of these co-located patients communities based on the perceptions and evaluations of their own member patients. Overall, financial benefits and health improvements are found to have a positive influence on increasing the chance of patients becoming committed to their communities in both short-term and long-term.

In the process of treatment, most patients tend to depend on the cluster and therefore few a strong attachment to it, especially women. In effect, due to unstable financial conditions, plus the fact that these patients often come from rural and remote areas and lack access to a lot of information regarding medical treatment, they will face many difficulties, notably extra expenses outside of treatment costs - which is even more worrying for chronic patients under long-term treatment. Living in patient communities can reduce unnecessary expenditure and save time for patients, as well as giving them a means of socialization. However, even though these pros give the impression that clusters are indispensable to patients, not all patients are willing to remain committed to their co-located community, even on short-term. In fact, their decision (to be or not to be committed) is influenced by their evaluation of the cluster's future growth prospects. More specifically, if they believe that their community can expand in the future, they will be more likely to be attached to the cluster, at least in the short term.

Member patients who faced or are facing financial hardships tend to be more committed to the community both on short- and long-term - during or after their treatment. For patients, uncertainties and unexpected medical costs are common; for this, they need a stable source of income so as not to spiral into destitution. The opportunity to work while being treated is therefore very important. However, such opportunities are rare, as ill people are often, if not always, excluded from the labour market. As a consequence, the jobs available to these patients end up making them even more vulnerable on many aspects: most of the time, they are odd jobs (motorbike taxi driver, street vendor, lottery ticket seller, etc.); the pay is very low; there is neither insurance nor any kind of legal contract - in fact, legally speaking, street vendors have been outlawed. It is therefore not a surprise that patients generally cannot cover their own needs during treatment, even if they manage to generate income. This explains why financial benefits are so highly appreciated among patients, and why patients whose financial needs - especially urgent ones - were covered by their community tend to show more commitment, at least during treatment.

Despite all the shortcomings that voluntary communities of colocated patients may show, the experiences of living in there suggest real values in improving patients' health conditions. As previously mentioned, co-location clusters are often the primary, if not unique, means of socialization for patients who come from afar and have limited resources regarding finance, information, and social connections. The mutual dependence favored by these communities increase the feeling of safety and social integration for each patient, all of which are crucial to their well-being and thus having good impacts on their health as well. The longer this connection persists, the more the bond between the patient and their community will deepen. In light of this, there is no surprise that patients will get attached to their cluster enough that they would be willing to remain supportive to the community even after their medical treatments have been completed, and that the longer they have lived with their co-located community, the more likely they are to be deeply attached. It is the emotional and material support provided by the patient cluster, quantified by the amout of time the patient has spent living within their community and qualified by the resulting health improvement that they feel, that decide the commitment of the patient to their cluster.

This result can be of considerable significance to policy makers and social workers in the healthcare sector, because it puts forward the the fact that patients choose to stick to the co-location clusters primarily for economic reasons, but also, perhaps subconsciously, for social integration. They are no doubt constantly looking for means to fight their financial hardships; at the same time, it is worth noting that these financial hardships result from none other than their lack of social connection and access to information, especially when many patients come to Hanoi from rural areas. As a consequence, the problem of destitution among patients requires complicated socioeconomic measures. For example, on the isssue of financing patients in need, not only the public but also the government mainly focuses on charity programs and in-kind donations (which turn out to be of much less use than money to patientse), while almost no discussion has been held on integrating patients into the labour market, under governmental protection, and help them generate their own income. Another problem worth fixing is the marginalization of patients. Patients are also potential donors, especially when they feel like they have received support from the community in their time of needs, be it financially or emotionally. If cured patients manage to find a secure source of income and continue to support their cluster, they will in turn give cluster members more chance to escape the vicious circle of poverty and illness. In this respect, socially integrating patients is a gradual, long-term solution to reduce poverty among patients.

Correspondence: Quan-Hoang Vuong, School of Business, FPT University, VAS Building, Block C, My Dinh 1, Tu Liem District, Hanoi, Vietnam.

E-mail: hoangvq@fsb.edu.vn

Key words: Voluntary communities, Co-location clusters, Financial benefits, Low-income countries, Vietnam

Acknowledgements: this article uses the data set that is collected with research assistance from Hanoi-based Vuong \& Associates. The authors thank the team, especially Dam Thu Ha, Nguyen Phuong, Do Thu Hang, Nghiem Phu Kien Cuong, Do Phuong Ngoc, and Vuong Thu Trang. The author expresses his deep gratitude to Prof. Rosella Levaggi - Editor of JPHRes - and two anonymous reviewers for constructive criticisms and helpful suggestions leading to substantial improvements of the manuscript.

Conflict of interest: the author declares have potential conflict of interests. Received for publication: 21 December 2016.

Accepted for publication: 6 March 2017.

CCopyright Q-H. Vuong, 2017

Licensee PAGEPress, Italy

Journal of Public Health Research 2017;6:788

doi:10.4081/jphr.2017.788

This work is licensed under a Creative Commons Attribution NonCommercial 4.0 License (CC BY-NC 4.0).

\section{References}

1. Khan MS, Guan BY, Audimulam J, et al. Economic interventions to improve population health: a scoping study of systematic reviews. BMC Public Health 2016;16:528.

2. Vuong QH, Ha N, Vuong TT. Health insurance thresholds and policy implications: a Vietnamese medical survey in 2015. Biomed Res 2017;28 [in press].

3. Anderson BO, Yip CH, Ramsey SD, et al. Breast Cancer in Limited-Resource Countries: Health Care Systems and Public Policy. Breast J 2006;12:S54-69. 
4. Neumann PJ, Palmer JA, Nadler E, et al. Cancer therapy costs influence treatment: a national survey of oncologists. Health Aff 2010;29:196-202.

5. Cipriano LE, Romanus D, Earle CC, et al. Lung cancer treatment costs, including patient responsibility, by disease stage and treatment modality, 1992 to 2003. Value Health 2011;14:41-52.

6. McIllmurray MB, Thomas C, Francis B, et al. The psychosocial needs of cancer patients: findings from an observational study. Eur J Cancer Care 2001;10:261-9.

7. Friedman LC, Kalidas M, Elledge R, et al. Optimism, social support and psychosocial functioning among women with breast cancer. Psychooncology 2006;15:595-603.

8. Suka M, Yamauchi T, Sugimori H. Help-seeking intentions for early signs of mental illness and their associated factors: comparison across four kinds of health problems. BMC Public Health 2016;16:301.

9. Hultberg EL, Lönnroth K, Allebeck P. Co-financing as a means to improve collaboration between primary health care, social insurance and social service in Sweden. A qualitative study of collaboration experiences among rehabilitation partners. Health Policy 2003;64:143-52.

10. Fisher ES. Building a medical neighborhood for the medical home. N Engl J Med 2008;359:1202-5.

11. Habib SS, Perveen S, Khuwaja HMA. The role of micro health insurance in providing financial risk protection in developing countries: a systematic review. BMC Public Health 2016;16:281.

12. Vuong QH, Vuong TT. Medical insurance and expenditure thresholds for Vietnamese patient satisfaction with healthcare services. Iran J Public Health 2017;46. [In press].

13. Vuong QH. Be rich or don't be sick: estimating Vietnamese patients' risk of falling into destitution. SpringerPlus 2015;4:529.

14. Cattell V. Poor people, poor places, and poor health: the mediating role of social networks and social capital. Soc Sci Med 2001;52:1501-16.

15. Long Q, Smith H, Zhang T, et al. Patient medical costs for tuberculosis treatment and impact on adherence in China: a systematic review. BMC Public Health 2011;11:393.

16. Vuong QH, Ha N. Do economic conditions and in-kind benefits make needy patients bond together? insights from crosssection data on clusters of co-located patients in Vietnam. Biomed Res 2017;28 [in press].

17. Tran BX, Nguyen LH, Nong VM, Nguyen CT. Health status and health service utilization in remote and mountainous areas in Vietnam. Health Qual Life Outcomes 2016;14:85.

18. Vuong QH, Nguyen TK. Vietnamese patients' choice of healthcare provider: in search of quality information. Int J Behav
Health Res 2015;5:184-212.

19. Vuong QH. Information expensiveness perceived by Vietnamese patients with respect to healthcare provider's choice. Acta Inform Med 2016;24:360-3.

20. Lehman AF, Possidente S, Hawker F. The quality of life of chronic patients in a state hospital and in community residences. Psychiatr Serv 1986;37:901-7.

21. Li MY, Yang YL, Liu L, Wang L. Effects of social support, hope and resilience on quality of life among Chinese bladder cancer patients: a cross-sectional study. Health Qual Life Outcomes 2016;14:73.

22. Clavarino AM, Lowe JB, Carmont SA, Balanda K. The needs of cancer patients and their families from rural and remote areas of Queensland. Aust J Rural Health 2002;10:188-95.

23. Hardeman W, Van Damme W, Van Pelt M, et al. Access to health care for all? User fees plus a Health Equity Fund in Sotnikum, Cambodia. Health Policy Plan 2004;19:22-32.

24. Blue-Howells J, McGuire J, Nakashima J. Co-location of health care services for homeless veterans: a case study of innovation in program implementation. Soc Work Health Care 2008;47:219-231.

25. Delva D, Vanoost S, Bijttebier P, et al. Needs and feelings of anxiety of relatives of patients hospitalized in intensive care units: implications for social work. Soc Work Health Care 2002;35:21-40.

26. Duggleby W, Williams A, Ghosh S, et al. Factors influencing changes in health related quality of life of caregivers of persons with multiple chronic conditions. Health Qual Life Outcomes 2016;14:81.

27. Ekbäck MP, Lindberg M, Benzein E, Årestedt K. Social support: an important factor for quality of life in women with hirsutism. Health Qual Life Outcomes 2014;12:183.

28. Vuong QH. Empirical probabilities of (non)optimal healthcare choice conditional on socioeconomic status and time consumption. Indian J Commun Health 2016;28:286-90.

29. Wen KY, Gustafson DH. Needs assessment for cancer patients and their families. Health Qual Life Outcomes 2004;2:11.

30. Vuong QH. Medical expenses matter most for the poor: evidence from a Vietnamese medical survey. Materia Socio Med 2016;28:429-431.

31. Agresti A. Categorical Data Analysis (3rd ed.). John Wiley, New York; 2013.

32. McCullagh P. Generalized linear models. Eur J Oper Res 1984;16:285-92.

33. Vuong QH, Napier NK, Tran TD. A categorical data analysis on relationships between culture, creativity and business stage: the case of Vietnam. Int J Trans Innov Syst 2013;3:4-24.

34. Walter W, Hauck Jr, Allan Donner. Wald's test as applied to hypotheses in logit analysis. J Am Stat Assoc 1977;72:851-3. 